\title{
Exposure Assessment of Dogs To Aflatoxins
}

\section{Erika Mitsuo Kiyoko Teixeira (I), Michele Frehse (II), Roberta Lemos Freire (II), Melissa Tiemi Hirozawa (I), Jaqueline Gozzi Bordini (I), Mario Augusto Ono (III), Elisa Yoko Hirooka (IV), Elisabete Yurie Sataque Ono (I)}

(I) UEL - Universidade Estadual de Londrina (Departamento de Bioquímica e Biotecnologia, Caixa Postal 10.011, 86057-970), (II) UEL - Universidade Estadual de Londrina (Departamento de Medicina Veterinária Preventiva, Caixa Postal 10.011, 86057-970), (III) UEL - Universidade Estadual de Londrina (Departamento de Ciências Patológicas, Caixa Postal 10.011, 86057-970), (IV) UEL - Universidade Estadual de Londrina (Departamento de Ciência e Tecnologia de Alimentos Caixa Postal 10.011, 86057-970)

\section{Resumo}

Aflatoxins are mycotoxins produced mainly by Aspergillus flavus, A.parasiticus and A.nomius which contaminate cereals and cereal products. Aflatoxins in feed are associated with toxic and carcinogenic effects in animals and can result in great economic losses. In dogs, aflatoxins can cause anorexia, depression, icterus, vomiting, diarrhea and sudden death. The aim of this study was to evaluate the exposure of dogs to aflatoxins through naturally contaminated feed. For this purpose occurrence of aflatoxins was in three feed types (Standard, Premium and Super Premium) intended for dogs $(n=81)$, collected from the residence of the owners in Northern Paraná State, Brazil. Aflatoxins were analyzed by a reversed phase isocratic high performance liquid chromatographic system, using a C-18 Luna Phenomenex column and acetonitrile:water $(25: 75, \mathrm{v} / \mathrm{v})$ as mobile phase. Aflatoxins were detected in $100 \%$ dog feed samples. Aflatoxin levels $\left(\mathrm{AFB}_{1}+\mathrm{AFB}_{2}+\mathrm{AFG}_{1}+\mathrm{AFG}_{2}\right)$ in Standard, Premium and Super Premium feed ranged from 0.16 to $5.39 \mu \mathrm{g} / \mathrm{kg}$ (mean $1.29 \mu \mathrm{g} / \mathrm{kg}$ ), 0.21 to $6.16 \mu \mathrm{g} / \mathrm{kg}$ (mean $0.49 \mu \mathrm{g} / \mathrm{kg}$ ) and 0.19 to $2.64 \mu \mathrm{g} / \mathrm{kg}$ (mean 0.53 $\mu \mathrm{g} / \mathrm{kg}$ ), respectively. The mean aflatoxin levels of Standard feed differed significantly from the Premium and Super Premium feed by the KruskalWallis test $(\mathrm{p}<0.05)$. In spite of the maximum allowed levels for aflatoxins have not been established for pet food, the maximum levels detected (6.16 $\mu \mathrm{g} / \mathrm{kg})$, were below the maximum tolerated limit $(20 \mu \mathrm{g} / \mathrm{kg})$ recommended 
by the Brazilian Association of Pet Products Industry (2013). The estimated mean daily intake of aflatoxins $(0.013 \mu \mathrm{g} / \mathrm{kg}$ bw/day) for dogs was below the acceptable daily intake ( $20 \mu \mathrm{g} / \mathrm{kg}$ body weight/day) and the pet safe dietary level $(6 \mu \mathrm{g} / \mathrm{kg}$ pet food), indicating that all the feed samples were considered safe for dogs concerning hepatotoxicity. Nevertheless a continuous monitoring of the feed producing chain is essential in order to minimize pet health hazards.

Palavras-Chave: aflatoxins, dog, mycotoxins, pet food

Agência de Fomento: CNPq (the Brazilian Government organization for grant aid and fellowship to Brazilian researchers) in association with MAPA ( Ministry of Agriculture, Livestock and Food Supply), the Araucária Foundation, Paraná Fund/SETI and CAPES 